tích hồi quy tuyến tính đa biến cho thấy nồng độ huyết sắc tố là một yếu tố độc lập ảnh hưởng đên chỉ số SLEPDAI $(\beta=-0,098 ; p=0,001$

- Ở thai phụ lupus, NLR và PLR có giá trị lần lượt là 3,96 và 159,66 . So với thai phụ khỏe mạnh, NLR không khác biệt, trong khi PLR cao hơn có ý nghĩa. So với nhóm lupus không mang thai NLR tăng cao hơn trong khi PLR thay đổi không đáng kể.

- NLR có tương quan thuận mức độ vừa với điểm SLEPDAI $(r=0,343)$. Trong khi đó PLR không cho thấy tương quan với chỉ số này.

- Trong dự báo sự xuất hiện của bệnh LBĐHT ở thai phụ, NLR và PLR có giá trị AUC lần lượt là $0,627$ (95\%CI: $0,519-0,735 ; p=0,040)$ và 0,729 (95\%CI: 0,627 - 0,822; $\mathrm{p}<0,001$ ).

\section{TÀI LIỆU THAM KHẢO}

1. Beyan, E., C. Beyan, and M.J.H. Turan, Hematological presentation in systemic lupus erythematosus and its relationship with disease activity. 2007. 12(3): p. 257-261.

2. Lee, Y.H. and G.G.J.J.o.R.D. Song, Association of neutrophil to lymphocyte ratio, platelet to lymphocyte ratio, and mean platelet volume with systemic lupus erythematosus disease activity: a meta-analysis. 2017. 24(5): p. 279-286.

3. Lateef, A. and M. Petri, Managing lupus patients during pregnancy. Best Pract Res Clin Rheumatol, 2013. 27(3): p. 435-47.

4. $\mathbf{W u}, \mathbf{Y}_{\text {., }}$ et al., Neutrophil-to-lymphocyte ratio (NLR) and platelet-to-lymphocyte ratio (PLR) were associated with disease activity in patients with systemic lupus erythematosus. 2016. 36: p. 94-99.

5. Hershko Klement, $A_{\text {., }}$ et al., Neutrophils to lymphocytes ratio and platelets to lymphocytes ratio in pregnancy: A population study. PLoS One, 2018. 13(5): p. e0196706.

6. Meng, $X$., et al., Determinant roles of gender and age on SII, PLR, NLR, LMR and MLR and their reference intervals defining in Henan, China: A posteriori and big-data-based. 2018. 32(2): p. e22228.

7. $\mathbf{Y u}, \mathbf{H}$., et al., Predictive value of the neutrophilto-lymphocyte ratio and hemoglobin insystemic lupus erythematosus. Exp Ther Med, 2018. 16(2): p. $1547-1553$.

8. Peirovy, A., et al., Clinical Usefulness of Hematologic Indices as Predictive Parameters for Systemic Lupus Erythematosus. Lab Med, 2020. 51(5): p. 519-528.

9. Yücel, B. and B. Ustun, Neutrophil to lymphocyte ratio, platelet to lymphocyte ratio, mean platelet volume, red cell distribution width and plateletcrit in preeclampsia. Pregnancy Hypertens, 2017. 7: p. 29-32.

\title{
ĐÁNH GIÁ CÁC YẾU TỐ LIÊN QUAN ĐẾN TRẦM CẢM Ở BỆNH NHÂN RỐI LOẠN CƯƠNG DƯO'NG
}

\section{TÓM TẮT}

Rối loạn cương dương (RLCD) là một rối loạn tình duc phổ biến, gây ảnh hưởng đến chất lượng cuộc sổng của bệnh nhân cũng như của đối tác. Nhiểu nghiên cứu chỉ ra rằng rối loạn cương dương có thể dânn đến trầm cảm (TC) khiến cho việc điều trị trở nên phức tạp và kém hiệu quả hơn. Chúng tôi tiến hành nghiên cứu trên 131 nam giới được chẩn đoán rối loạn cương dương để đánh giá trầm cảm và các yếu tố liển quan. Kết quả nghiên cứu của chúng tôi cho thấy tuổi trung bình của nhóm bệnh nhân có rối loạn cướng dương là $45 \pm 14,8$. Tỉ lệ trầm cảm của những bệnh nhân rối loạn cương dương là 38,2\%. Các yếu tố bao gồm tuổi dưới 40, không kết hôn và thủ dâm làm tăng nguy cơ xuất hiện của trầm cảm $(p<0,05)$. dâm.

Tư khóa: trầm cảm, rối loạn cương dương, thủ

\footnotetext{
${ }^{1}$ Trường Đại học Y Hà Nội

Chịu trách nhiệm chính: Dương Khánh Duy

Email: duyrpmed@gmail.com

Ngày nhận bài: 21.6.2021

Ngày phản biện khoa học: 18.8.2021

Ngày duyệt bài: 24.8.2021
}

\section{SUMMARY \\ EVALUATE SEVERAL FACTORS ASSOCIATED WITH DEPRESSION IN PATIENTS WHO HAVE ERECTILE DYSFUNCTION}

Erectile dysfunction (ED) is a common sexual dysfunction which impacts on the quality of life of both patients and their partners. Many studies have shown that erectile dysfunction can lead to depression, making treatment more complicated and less effective. We conducted a study on 131 men who had erectile dysfunction to assess depression and associated factors. The results of our study showed that the mean age of the group of patients with erectile dysfunction was $45 \pm 14.8$. The rate of depression among patients with erectile dysfunction was $38.2 \%$. Factors including age under 40, unmarried and masturbation are associated with depression $(p<0,05)$.

Keyword: depression, erectile dysfunction, masturbation.

\section{I. ĐĂT VẤN ĐỀ}

Rối loan cương dương (RLCD)là rối loan tình dục phổ biến ở nam giới. Theo ước tính đển năm 2025, số lượng nam giới mắc RLCD sẽ đạt 322 triệu người[1]. Mặc dù RLCD không ảnh hưởng 
tới các chức năng thực thể nhưng lại có thể gây ảnh hưởng sâu sắc tới đời sống tinh thần của nam giới cũng như hạnh phúc gia đình họ. RLCD gặp trong nhiều bệnh lí khác nhau, có nguyên nhân thực thể và nguyên nhân tâm lí, hoặc do kết hợp. Các nguyên nhân thực thể chính của RLCD bao gồm bệnh lí chuyển hóa và bệnh lí tim mạch. Đây là những bệnh lí phổ biến ở các nước phát triển, tuy nhiên gần đây đang ngày càng gia tăng ở nước ta.

Bên cạnh RLCD, trầm cảm (TC) cũng là một vấn đề sức khỏe thường gặp trong xã hội hiện đại. Các biểu hiện của TC thường xuất hiện là buồn chán, mệt mỏi, giảm năng lượng, mất quan tâm thích thú trong các hoạt động. Từ lâu TC đã được coi là một trong những nguyên nhân tâm căn chính gây ra rối loạn cương dương. Ngoài ra, nhiều nghiên cứu gần đây chỉ ra rằng RLCD có liên quan đến sự khởi phát của các triệu chứng TC.

Trên thế giới, mối liên quan giữa các rối loạn tâm thần và RLCD từ lâu đã được nghiên cứu, trong đó có rối loạn TC. Nhiều khuyến cáo đã đưa ra việc tầm soát TC ở những bệnh nhân mắc RLCD và ngược lại, đánh giá chức năng cương ở những bệnh nhân có TC. Ở Việt Nam, nhiêuu nghiên cứu đã được tiến hành trền những bệnh nhân RLCD nhưng chủ yếu chỉ đánh giá các nguyên nhân thực thể mà chưa đề cập đến rối loạn TC. Vì những lí do trên, chúng tôi thực hiện nghiên cứu với mục tiêu "Đánh giá các yếu tố liên quan đến trầm cảm ở bệnh nhân rối loạn cương dương".

\section{II. ĐỐI TƯƠ'NG VÀ PHƯƠNG PHÁP NGHIÊN CỨU}

2.1 Đối tượng nghiên cứu. Tất cả bệnh nhân đến khám và điều trị rối loạn cương dương tại Khoa Nam học và Y học Giới tính - Bệnh viện Đại học Y Hà Nội.

Tiêu chuân lựa chơn:

- Bệnh nhân đủ 18 tuổi, đã quan hệ tình dục ổn định

- Được chẩn đoán có rối loạn cương dương

Tiêu chuẩn loại trư::

- Có tiền sử chẩn đoán và điều trị bất kì rối loạn tâm thần nào trước đây

- Bệnh nhân khiếm khuyết giao tiếp, khiếm thính (gây khó khăn trong hỏi bệnh và khám bệnh)

- Bệnh nhân không đồng ý tham gia nghiên cứu

- Thiếuthông tin cần thiết cho nghiên cứu

2.2 Địa điểm và thời gian nghiên cứu

- Địa điểm: Khoa Nam học và Y học Giới tính

- Bệnh viện Đại học Y Hà Nội.

- Thời gian: Nghiên cứu được tiến hành từ

\section{8/2020 đến 05/2021}

2.3 Phương pháp nghiên cứu:

- Mô tả cắt ngang

- Lấy mẫu tiến cứu

- Chon mẫu có chủ đích

2.4. Quy trình nghiên cứu. Nam giới trên 18 tuổi đến khám tại Khoa Nam học - Y học Giới tính Bênh viên Đai hoc $Y$ Hà Nôi sau khi đước sàng lọc, phẩn loại, khai thác thông tin về tiền sử, bệnh sử sẽ được phỏng vấn sâu nhẳm phát hiện các bất thường về chức năng tình dục như tần số quan hệ tình dục, tần số thủ dâm và chức năng cương dương. Các tiêu chuẩn chẩn đoán RLCD bao gồm (i) không có khả năng đạt được và duy trì cương dương để thỏa mãn nhu cầu tình dục và (ii) xuất hiện thường xuyên trong vòng 3 tháng trở lại. Những bệnh nhân phù hợp với tiêu chuẩn trên được đánh giá lâm sàng về tâm thần kết hợp sử dụng bộ câu hỏi tự đánh giá PHQ-9. Bệnh nhân được chẩn đoán TC dựa theo tiêu chuẩn của Phân loại bệnh quốc tế lẩn thứ 10 (ICD-10) khi có ít nhất hai triệu chứng chính và ít nhất hai triệu chứng phổ biển diễn ra liên tục trong khoảng thời gian 2 tuần.

Một số tiêu chuẩn đánh giá khác:

- Suy giảm testosterone: khi nồng đô testosterone toàn phần trong máu giảm dưới $12 \mathrm{nmol} / \mathrm{L}$

- Thủ dâm: Bệnh nhân trong nghiên cứu được đánh giá về tình trạng thủ dâm trong 03 tháng gần nhất, câu trả lời có hoặc không và những đối tượng có thủ dâm sẽ được tiếp tục hỏi về tần số thủ dâm/tuần

- Số lần quan hệ: đánh giá trong 3 tháng gần nhất, với đơn vị số lần/tháng

2.5. Xử lý số liệu. Kết quả của nghiên cứu được xử lý bằng phềm mềm SPSS 20.0. Khi so sánh hai nhóm, thuật toán T-student test được dùng đối với biến phân bố chuẩn, thuật toán Mann Whitney test được dùng với biến phân bố không chuẩn. Fisher's exact test được dùng để kiểm định khác biêt về tỷ lệ giữa các nhóm. Sử dụng thuật toán ANOVA test đối với biến phân bố chuẩn, sử dụng thuật toán Kruskal Wallis test đối với biến phân bố không chuẩn. Mô hình hồi quy logistic được dùng để xác định ORtỉ lệ TC giữa các nhóm. Kết quả được coi là có ý nghĩa thống kê với giá trị $\mathrm{p}<0,05$ (độ tin cậy 95\%).

2.6. Đaoo đức nghiên cứu. Số liệu được mã hóa để giữ bí mật cho thông tin bệnh nhân. Đây là nghiên cứu mô tả không can thiệp chẩn đoán và điều trị nên không làm ảnh hưởng đến sức khỏe người bệnh. Bệnh nhân tự nguyện đồng ý tham gia nghiên cứu. 
III. KẾT QUẢ NGHIÊN CỨU

3.1 Đặc điểm chung của nhóm nghiên cứu

Bảng 1: Đặc điểm chung của đôî tượng nghiên cứlu

\begin{tabular}{|c|c|c|c|}
\hline Đăc điểm & $\begin{array}{c}\text { Trung } \\
\text { bình } \pm \text { SD }\end{array}$ & $\begin{array}{c}N \\
(\%)\end{array}$ & $\begin{array}{l}\text { Min- } \\
\text { Max }\end{array}$ \\
\hline Tuổi (năm) & $45 \pm 14,8$ & & $18-83$ \\
\hline$<40$ & & $52(39,7)$ & \\
\hline$\geq 40$ & & $79(60,3)$ & \\
\hline \begin{tabular}{|c|}
$\begin{array}{c}\text { Tuối quan hề } \\
\text { tình dục lần đầu } \\
\text { (tuổi) }\end{array}$ \\
\end{tabular} & $21,8 \pm 3,2$ & & $13-36$ \\
\hline$<18$ & & $11(8,4)$ & \\
\hline$\geq 18$ & & $120(91,6)$ & \\
\hline \multicolumn{4}{|l|}{$\begin{array}{c}\text { Số đối tác quan } \\
\text { hệ (người) }\end{array}$} \\
\hline 1 & & $106(80,9)$ & \\
\hline 2 & & $16(12,2)$ & \\
\hline$\geq 3$ & & $8(6,1)$ & \\
\hline \multicolumn{4}{|l|}{ Thủ dâm } \\
\hline Có & & $32(24,4)$ & \\
\hline Không & & $99(75,6)$ & \\
\hline $\begin{array}{l}\text { Tân số quan hệ } \\
\text { tình dục (/tháng) }\end{array}$ & $4 \pm 3,5$ & & $0-20$ \\
\hline$<4$ & & $78(59,5)$ & \\
\hline$\geq 4$ & & $53(40,5)$ & \\
\hline BMI $\left(\mathrm{kg} / \mathrm{m}^{2}\right)$ & & & $\begin{array}{l}17,9- \\
29,4 \\
\end{array}$ \\
\hline
\end{tabular}

\begin{tabular}{|c|c|c|c|}
\hline$<18$ & & $1(0,8)$ & \\
\hline $18-23$ & & $56(42,7)$ & \\
\hline$>23$ & & $74(56,5)$ & \\
\hline
\end{tabular}

Nhận xét: Tuổi trung bình của đối tượng nghiên cứu là $45 \pm 14,8$; phần lớn thuộc nhóm từ 40 tuổi trở lên chiếm 60,3\%. Tuổi quan hê tình dục lần đầu của đối tượng nghiên cứu là $21,8 \pm 3,2$; chủ yếu thuộc nhóm từ 18 tuổi trở lên $(91,6 \%)$. Đa số các bệnh nhân nghiên cứu không thủ dâm (75,6\%), quan hệ tình dục dưới 4 lần/tháng $(59,5 \%)$ và thừa cân (56,5\%). cứu

3.2 Tỉ lệ trâm cảm của đối tượng nghiên

Bảng 2: Tỉ lệ trâm cảm của đôî tượng nghiên cứu

\begin{tabular}{|c|c|c|}
\hline Phân loại & N & \% \\
\hline Không trâm cảm & 81 & 61,8 \\
\hline Có trâm cảm & 50 & 38,2 \\
\hline Trầm cảm nhẹ & 33 & 25,2 \\
\hline Trâm cảmvừa & 13 & 9,9 \\
\hline Trâm câmnặng & 4 & 3,1 \\
\hline Tống & 131 & 100 \\
\hline
\end{tabular}

Nhận xét: Trong nghiên cứu của chúng tôi, 50 bệnh nhân có trầm cảm chiếm tỉ lệ $38,2 \%$. Trong đó 33 bệnh nhân có biểu hiện trầm cảm nhẹ chiếm $25,2 \%$ và chỉ có 4 bệnh nhân trầm cảm nặng chiếm $3,1 \%$.

3.3 So sánh một số đặc điểm giữa nhóm trâm cảm và không trâm cảm

Bảng 3: So sánh một số đặc điểm của nhóm bệnh nhân có trầm cảm và không có tràm cảm

\begin{tabular}{|c|c|c|c|}
\hline Đăc điểm & Trâm cảm & Không trâm cảm & \\
\hline tọc anem & Trung bình \pm SD & Trung bình \pm SD & $\mathbf{p}$ \\
\hline Tuối (năm tuối) & $39,32 \pm 13,59$ & $48,48 \pm 14,44$ & $<0,001$ \\
\hline BMI $\left(\mathrm{kg} / \mathrm{m}^{2}\right)$ & $23,06 \pm 2,51$ & $23,4 \pm 2,5$ & 0,447 \\
\hline Tuổi quan hệ lần đâu (năm tuối) & $21,54 \pm 3,57$ & $21,98 \pm 3,81$ & 0,67 \\
\hline Tân số quan hệ (lần/tháng) & $3,98 \pm 3,59$ & $3,97 \pm 3,43$ & 0,986 \\
\hline Tần số thủ dâm (lần/tuần) & $0,67 \pm 1,06$ & $0,17 \pm 0,53$ & 0,003 \\
\hline IIEF-5 (điểm) & $12,52 \pm 3,69$ & $12,48 \pm 3,79$ & 0,282 \\
\hline Thang điểm SqoL-M (điểm) & $19,90 \pm 5,61$ & $27,74 \pm 8,03$ & $<0,001$ \\
\hline PHQ9 (điểm) & $9,02 \pm 3,531$ & $2,51 \pm 2,044$ & $<0,001$ \\
\hline Testosterone $(\mathrm{nmol} / \mathrm{L})$ & $17,92 \pm 7,09$ & $16,44 \pm 6,87$ & 0,282 \\
\hline $\mathrm{LH}(\mathrm{mU} / \mathrm{mL})$ & $7,35 \pm 9,22$ & $6,03 \pm 3,19$ & 0,281 \\
\hline Estradiol $(\mathrm{mU} / \mathrm{mL})$ & $129,33 \pm 44,11$ & $119,5 \pm 43,17$ & 0,26 \\
\hline
\end{tabular}

Nhận xét: So với nhóm bệnh nhân không có trầm cảm, nhóm bệnh nhân có trầm cảm có tuối trung bình thấp hơn, tần số thủ dâm lớn hơn và chất lượng đời sống tình dục thấp hơn có ý nghĩa thống kê với $p<0,05$.

3.3 Khảo sát một số yếu tố liên quan đến rôi loạn trâm cảm ở bệnh nhân rối loạn cương dương Bảng 4: Một sồ yếu tố liên quan đến rôi loạn trâm cảm ở bệnh nhân rôi loạn cương dương

\begin{tabular}{|c|c|c|c|c|c|}
\hline \multirow{2}{*}{ Đặc điểm } & & \multicolumn{2}{|c|}{ Rối loạn trâm cảm } & \multirow{2}{*}{ pOR } & p \\
\cline { 3 - 4 } & & $\begin{array}{c}\text { Không trâm cảm } \\
\text { [n (\%)] }\end{array}$ & $\begin{array}{c}\text { Trâm cảm } \\
{[\mathbf{n}(\%)]}\end{array}$ & & \\
\hline Tuối & $<40$ tuối & 44,2 & 55,8 & $\mathbf{1}$ & $\mathbf{0 , 0 0 1}$ \\
\hline (năm tuổi) & $\geq 40$ tuổi & 73,4 & 26,6 & $\mathbf{0 , 2 8 7}$ & $\mathbf{2}$ \\
\hline
\end{tabular}


VIETNAM MEDICAL JOURNAL N² - SEPTEMBER - 2021

\begin{tabular}{|c|c|c|c|c|c|}
\hline Khu vực & $\begin{array}{l}\text { Nông thôn } \\
\text { Thành thị }\end{array}$ & $\begin{array}{l}59,7 \\
64,1\end{array}$ & $\begin{array}{l}40,3 \\
35,9\end{array}$ & $\begin{array}{c}1 \\
0,831\end{array}$ & 0,37 \\
\hline Hút thuốc lá & $\begin{array}{l}\text { Không } \\
\text { Có }\end{array}$ & $\begin{array}{c}62,5 \\
60\end{array}$ & $\begin{array}{l}37,5 \\
40\end{array}$ & $\begin{array}{c}1 \\
1,111\end{array}$ & 0,474 \\
\hline $\begin{array}{l}\text { Thủ dâm } \\
\text { (lần/tuânn) }\end{array}$ & $\begin{array}{l}\text { Không } \\
\text { Có }\end{array}$ & $\begin{array}{l}70,7 \\
34,4 \\
\end{array}$ & $\begin{array}{l}29,3 \\
65,6 \\
\end{array}$ & $\begin{array}{c}1 \\
4,608 \\
\end{array}$ & $\begin{array}{c}< \\
0,001\end{array}$ \\
\hline $\begin{array}{l}\text { Thời gian mắc } \\
\text { RLCD (năm) }\end{array}$ & $\begin{array}{l}\leq 1 \text { năm } \\
>1 \text { năm }\end{array}$ & $\begin{array}{l}59,0 \\
64,3\end{array}$ & $\begin{array}{l}41,0 \\
35,7\end{array}$ & $\begin{array}{c}1 \\
0,8\end{array}$ & 0,536 \\
\hline $\begin{array}{l}\text { Giảm nhu cầu } \\
\text { tình dục }\end{array}$ & $\begin{array}{l}\text { Không } \\
\text { Có }\end{array}$ & $\begin{array}{c}60,0 \\
62,2 \%\end{array}$ & $\begin{array}{c}40,0 \\
37,8 \%\end{array}$ & $\begin{array}{c}1 \\
0,913\end{array}$ & 0,855 \\
\hline $\begin{array}{c}\text { Tình trang hôn } \\
\text { nhân }\end{array}$ & $\begin{array}{l}\text { Độc thân } \\
\text { Kết hôn }\end{array}$ & $\begin{array}{c}32 \\
68,9\end{array}$ & $\begin{array}{c}68 \\
31,1\end{array}$ & $\begin{array}{c}1 \\
0,213\end{array}$ & 0,001 \\
\hline $\begin{array}{l}\text { Sử dụng chất } \\
\text { gây nghiện }\end{array}$ & $\begin{array}{l}\text { Không } \\
\text { Có }\end{array}$ & $\begin{array}{l}68,2 \\
55,4\end{array}$ & $\begin{array}{l}31,8 \\
44,6\end{array}$ & $\begin{array}{c}1 \\
1,726\end{array}$ & 0,133 \\
\hline $\begin{array}{l}\text { Suy giảm } \\
\text { testosterone }\end{array}$ & $\begin{array}{l}\text { Không } \\
\text { Có }\end{array}$ & $\begin{array}{c}59,3 \\
69\end{array}$ & $\begin{array}{c}40,7 \\
31\end{array}$ & $\begin{array}{c}1 \\
0,655\end{array}$ & 0,358 \\
\hline
\end{tabular}

Nhận xét: Những bệnh nhân dưới 40 tuổi, có thủ dâm và độc thân có tỉ lệ trầm cảm cao hơn có ý nghĩa thống kê với $p<0,05$.

\section{BÀN LUẬN}

Tuổi trung bình của đối tượng nghiên cứu là $45 \pm 14,8$. Đây là độ tuổi mà nam giới có nhiều vấn đề liên quan đển các nguyên nhân cơ thể của rối loạn cương dương đặc biệt là các rối loạn chuyển hóa. Điều này cũng được phản ánh qua chỉ số BMI khi hơn một nửa số đối tượng nghiên cứu thừa cân nhe $(56,5 \%)$. Trong nghiên cứu của chúng tôi, nhóm bệnh nhân từ 40 tuổi chiếm đa số với $60,3 \%$. Các nghiên cứu về RLCD trước đây cũng tập trung vào độ tuổi này với hai nghiên cứu nổi bật là MMAS và EMAS được tiến hành trên nam giới lớn tuổi tại Mỹ và châu Âu [2], [3]. Nhóm bệnh nhân dưới 40 tuổi cũng chiếm tỉ lệ khá lớn với 39,7\% cho thấy xu hướng trẻ hóa của các bệnh nhân RLCD. Theo nghiên cứu tại trung tâm Nam học và $Y$ học giới tính của đại học Florence, tỉ lệ nam giới dưới 40 tuổi đến khám vì rối loạn cương dương đã tăng từ $5 \%$ năm 2010 lên $15 \%$ năm 2015[4].

Tỉ lệ trầm cảm của đối tượng nghiên cứu của chúng tôi là $38,2 \%$ trong đó đa số là trầm cảm nhẹ và vừa. Kết quả này cũng tương đồng với kết quả nghiên cứu của Yeong trên nam giới tại Hàn Quốc (39\%)[5]. Trầm cảm kết hợp với rối loạn cương dương sẽ làm nặng hơn triệu chứng của cả hai rối loạn và khiến cho việc điều trị trở nên khó khăn hơn.

So sánh giữa hai nhóm có trầm cảm và không có trầm cảm, chúng tôi nhận thấy nhóm bệnh nhân có trầm cảm có tuổi trung bình thấp hớn, tần số thủ dâm lớn hơn và chất lượng đời sống tình dục thấp hơn có ý nghĩa thống kê với $\mathrm{p}<$ 0,05 . Hơn nữa khi tiến hành đánh giá một số yếu tố liên quan đến trầm cảm ở bệnh nhân rối loạn cương dương, chúng tôi nhận thấy các yếu tố tuổi, thủ dâm và không kết hôn làm tăng nguy cơ trầm cảm ở bệnh nhân rối loạn cương dương.

Đối với các bệnh nhân trầm cảm, giai đoạn đầu tiên thường xuất hiện từ 20-40 tuổi, với tuổi khởi phát trung bình là 25 tuổi[6]. Nam giới ở độ tuổi này có nhu cầu tình dục lớn, tuy nhiên lại chịu nhiều áp lực từ kinh tế và công việc. Chính vì vậy thất bại trong hoạt động tình dục do rối loạn cương dương có thể là một yếu tố làm khởi phát trầm cảm. Nam giới khổng kết hôn (bao gồm nhóm chưa kết hôn hoặc đã li hôn/góa) cũng có nguy cơ trầm cảm cao hơn. Điêuu này phù hợp với mối liên quan giữa trầm cảm và tình trạng hôn nhân từ lâu đã được biết đến là mối quan hệ hai chiều: những người độc thân được báo cáo có tỉ lệ trầm cảm cao hơn và ngược lại, trầm cảm là nguyên nhân của hôn nhân không hạnh phúc[7].

Thủ dâm là một hành vi tình dục an toàn giúp giải quyết vấn đề thỏa mãn nhu cầu mà không có nguy cơ từ các bệnh lây truyền qua đường tình dục. Nam giới có RLCD né tránh quan hệ tình dục có thể tìm đến thủ dâm như một hình thức để đạt được khoái cảm và đồng thời duy trì chức năng cương. Tuy nhiên, thủ dâm là hoạt động tình dục một mình và không có đối tác, có thể làm thúc đẩy thêm cảm giác cô đơn và tự ti đặc biệt trong tình huống người nam giới thất bại sự cương dương trong quá trình thủ dâm. Chính vì vậy khi có biểu hiện của RLCD nam giới nên đi khám để được tư vấn và điều trị kịp thời của bác sĩ chuyên khoa. Đồng thời, các triệu chứng của trầm cảm cũng cần phải được sàng lọc trên các bệnh nhân RLCD, đặc biệt là những bệnh nhân trẻ tuổi. 


\section{KẾT LUÂN}

Trầm cảm xuất hiên với tỉ lệ tương đối cao ở những bệnh nhân có RLCD, người bệnh có rối loạn cương dương cần được sàng lọc các triệu chứng của trầm cảm, nhất là người bệnh có độ tuổi dưới 40 tuổi.

\section{TÀI LIÊU THAM KHẢO}

1. S. Nimesh, R. Tomar, M. Kumar, N. Tyagi, and P. K. Shukla, "Erectile Dysfunction: An Update," Adv. Medical, 'Dent. Heal. Sci., vol. 2, no. 1, pp. 04-07, 2019, doi: 10.5530/amdhs.2019.1.3.

2. H. A. Feldman, I. Goldstein, D. G. Hatzichristou, R. J. Krane, and J. B. McKinlay, "Impotence and its medical and psychosocial correlates: results of the Massachusetts Male Aging Study.," J. Urol., vol. 151 , no. 1 , pp. 54-61, Jan. 1994, doi: $10.1016 / \mathrm{s} 0022-5347(17) 34871-1$.
3. D. M. Lee et al., "Cohort profile: The european male ageing study," Int. J. Epidemiol., vol. 42, no. 2, pp. 391-401, 2013, doi: 10.1093/ije/dyr234.

4. G. Rastrelli and M. Maggi, "Erectile dysfunction in fit and healthy young men: Psychological or pathological?," Translational Andrology and Urology, vol. 6, no. 1. AME Publishing Company, pp. 79-90, 2017, doi: 10.21037/tau.2016.09.06.

5. J. Y. Jeong, S. K. Lee, Y. W. Kang, S. N. Jang, Y. J. Choi, and D. H. Kim, "Relationship between ED and depression among middle-aged and elderly men in Korea: Hallym aging study," Int. J. Impot. Res., vol. 23, no. 5, pp. 227-234, 2011, doi: 10.1038/ijir.2011.32.

6. G. S. Malhi and J. J. Mann, "Depression," Lancet, vol. 392, no. 10161, pp. 2299-2312, 2018, doi: 10.1016/S0140-6736(18)31948-2.

7. H. I. Sadock, B. J., Sadock, V. A., Ruiz, P., \& Kaplan, Kaplan and Sadock's comprehensive textbook of psychiatry, 10th ed. Wolters Kluwer., 2017.

\section{NGHIÊN CỨU ĐĂC ĐIỂM LÂM SÀNG VÀ HÌNH ẢNH SIÊU ÂM, HìnH ẢNH CộNG HƯởNG TỪ CỦA LAC NộI MẠC TRONG CƠ TỬ CUNG}

\section{TÓM TẮT}

Mục tiêu: Mô tả các đặc điểm lâm sàng, hình ảnh trên siêu âm qua âm đạo (TVS) và cộng hưởng từ của lạc nội mạc trong cơ tử cung (adenomyosis). Phương pháp nghiên cứu: 31 bệnh nhân nữ đi khám phụ khoa hoắc vô sinh do có triêuu chứng lâm sàng nghi ngờ LNMTCTC, được siêu âm qua đường âm đạo, chụp cộng hưởng từ tử cung tại bệnh viện Đại học Y Hà Nội và bệnh viện đa khoa Tâm Anh và đồng ý tham gia nghiên cứu. Kết quả: Có 31 bênh nhân vớituổi trung bình là 42,03 $\pm 6,4$ tuổi. Triệu chứng đau bunng kinhchiếm khoảng $90.3 \%$. Có $27 \%$ trường hợp có hình ảnh LNMTCTC trên TVS. Hình ảnh trên siêu âm bao gồm: nhiều nang nhỏ trong lớp cơ tử cung chiếm 83,9\%, các đảo tăng âm trong cơ tử cung chiếm 83,9\%, đường hoặc chồi tăng âm dưới nội mạc tử cung là $32,3 \%$, hình ảnh bóng rẻ quat là $78,1 \%$, vùng nối không đều chiếm $12,9 \%$ và hình ảnh tưới máu lan tỏa trên siêu âm Doppler là $80,7 \%$. Vi trí của LNMTCTC xuất hiện ở thành trước $(37,0 \%)$, thành sau $(81,5 \%)$, thành phải $(40,7 \%)$, thành trái $(48,2 \%)$ và đáy tư cung $(63,0 \%)$. LNMTCTC khu trú chiếm $14,81 \%$, lan tỏa chiếm $66,7 \%$ và u tuyến cơ

${ }^{1}$ Trường Đại học Y Hà nội

²Bênh viện đa khoa Tâm Anh

${ }^{3}$ Bênh viện Đại Học Y Hà nội

Chị trách nhiệm chính: Hoàng Đình Âu

Email: hoangdinhau@gmail.com

Ngày nhận bài: 23.6.2021

Ngày phản biên khoa họ: 19.8.2021

Ngày duyệt bài: 25.8.2021
Đặng Hoàng Hà ${ }^{1}$, Lê Hoàng ${ }^{2}$, Hoàng Đình $\hat{A ̂ u}^{3}$

(adenomyoma) chiếm 18,5\%. Sự xuất hiện của nang trong LNMTCTC chiếm $100 \%$. Tốn thương nằm ở vị trí lớp trongcơ tử cung $(77,8 \%)$, lớp giữa cơ tử cung $(96,3 \%)$ và lớp ngoài cơ tử cung $(88,9 \%)$. Mức đô của bệnh mức độ nhe chiếm 22,2\%; mức độ vừa là 33,3\% và̀ năng chiếm $44,5 \%$. Đường kính trung bình của LNMTCTC là $41,1 \pm 15 \mathrm{~mm}$. Đặc điểm trên hình ảnh MRI: tín hiêu cường đô hỗn hợp trên T1W là 64,5\%, trên $\mathrm{T} 2 \mathrm{~W}$ là $48,4 \%$, tăng tín hiệu trên T1FS là $9,7 \%$ liên quan với tình trạng chảy máu. Độ dày trung bình của vùng nối là $22,3 \pm 17,5 \mathrm{~mm}$. Các bệnh vùng chậu đi kèm với LNMTCTC: u xơ tử cung $(32,3 \%)$, u nang buồng trứng đơn thuần $(9,7 \%)$, nang lạc nội mạc tư cung trong buồng trứng $(32,3 \%)$, u quái buồng trứng $(6,5 \%)$. Kết luâan: Trong các trường hợp nghi ngờ LNMTCTC trên lâm sàng, siêu âm đường âm đaolà phương tiện chẩn đoán được lựa chọn đầu tiên. MRI có thể được xem xét khi TVŚ không thể đánh giá đước.MRI là phương phápchẩn đoán chính xác cho LNMTCTC, cho phép phát hiện các bênh lý vùng chậu liên quan. Đặc điểm quan trọng nhất trên MRI trong chẩn đoán là xác định độ dày của vùng nối trên $12 \mathrm{~mm}$.

Tư khóa: lac nôi mac trong cơ tử cung, hình ảnh cộng hưởng từ, siêu âm qua đường âm đạo

\section{SUMMARY}

\section{RESEARCH CLINICAL CHARACTERISTICS AND IMAGE FEATURES OF ULTRASOUND} AND MRI OF ADENOMYOSIS

Objective: Describle the clinical symptoms, transvaginal ultrasound (TVS) and MRI features of adenomyosis. Methods: Thirty - one females patients was suspecteduterine adenomyosis in clinic, diagnosed 